\title{
Effects of amygdaloid lesions in rats on food and water intake and body weight under varied ambient temperatures*
}

\author{
ERNEST D. KEMBLE and JENNIFER A. NAGEL \\ University of Minnesota, Morris, Morris, Minnesota 56267
}

\begin{abstract}
Food and water intake and body weight were measured in amygdala-lesioned and control Ss under three $\left(70^{\circ}, 60^{\circ}\right.$, and $\left.80^{\circ} \mathrm{F}\right)$ ambient temperature conditions. Both experimental and control Ss responded similarly to these manipulations with no suggestion of lesion-induced deficiency. These data are consistent with other research, which suggests that damage to basolateral portions of the amygdala leaves daily food and water regulatory mechanisms intact.
\end{abstract}

Although a number of experiments (e.g., Grossman, 1964) have implicated the amygdaloid complex in food and water regulation, the anatomical locus within this structure and the test conditions under which these deficiencies occur are unclear (see, e.g., Goddard, 1964). Previous research in our laboratory has indicated that amygdaloid lesions at sites which produce decreased reactivity to sucrose and quinine solutions (Kemble \& Schwartzbaum, 1969) and altered food rewards (Kemble \& Beckman, 1970) and which interfere with formation of a learned taste aversion (Kemble \& Nagel, 1973) have no discernible effects on daily food and water consumption, adaptation to food and water deprivation schedules, or adaptation to cellulose-adulterated food (Kemble, unpublished observations). This experiment examines the effects of amygdaloid lesions on body weight and food and water intake under varied ambient temperatures.

\section{METHODS}

The Ss were 15 experimentally naive male albino rats (Holtzman Co.), weighing 288-334 g at the time of surgery. Amygdaloid lesions $(\mathrm{N}=7)$ were stereotaxically placed by passing $2.0 \mathrm{~mA}$ anodal dc through the uninsulated tip of a stainless steel pin. Two Ss received control operations, and five Ss received scalp incisions only. Further details are contained in earlier publications (e.g., Kemble \& Beckman, 1970).

All Ss were individually housed with continuous fluorescent illumination in Wahman (LC-28) cages adapted to hold 100-ml drinking cylinders and covered food dishes. Ss were given ad lib access to powdered food and water throughout the experiment. Temperature was controlled at $70^{\circ} \mathrm{F}\left(69^{\circ}-75^{\circ}\right)$ and $80^{\circ} \mathrm{F}$ $\left(77^{\circ}-84^{\circ}\right)$ by a portable air-conditioning unit and at $60^{\circ} \mathrm{F}$ $\left(53^{\circ}-67^{\circ}\right)$ by a commercial refrigeration unit. Food and water intake were recorded daily for 8 days at $70^{\circ} \mathrm{F}$, for 9 days at $60^{\circ} \mathrm{F}$, and finally for 9 days at $80^{\circ} \mathrm{F}$.

At the conclusion of testing, cresyl violet-stained coronal sections were prepared through the lesion area of all experimental Ss.

\section{RESULTS AND DISCUSSION}

All experimental Ss sustained bilateral amygdaloid

*The authors would like to thank Mary Ramsey, who aided in data collection. Send reprint requests to: Ernest Kemble, Division of Social Sciences, University of Minnesota, Morris, Morris, Minnesota 56267. damage which was similar in size and placement to previously reported lesions (Kemble \& Beckman, 1970; Kemble \& Nagel, 1973). Briefly, damage was most consistently focused in the ventro-lateral quadrant of the structure, in the area of the lateral and basal amygdaloid nuclei and their underlying pyriform cortex. There was no obvious relation between lesion size or placement and performance. Reconstructions of two representative lesions from this experiment are presented in a report of a later investigation using these Ss (Kemble, in press).

The temperature changes employed in this experiment produced easily discernible effects on food and water intake and body weight. All measures increased steadily during $70^{\circ} \mathrm{F}$ testing $(\mathrm{Fs}=3.76-25.67$, df $=7 / 92$, ps $<.01)$. During $60^{\circ} \mathrm{F}$ testing, food and water intake continued to increase $(\mathrm{Fs}=3.71-3.78$, df $=8 / 105$, ps $<.01)$, while body weight declined steadily $(F=6.49$, $\mathrm{df}=8 / 105, \mathrm{p}<.01)$. During $80^{\circ} \mathrm{F}$ testing, body weight and food and water intake also increased steadily ( $\mathrm{Fs}=$ 2.11-7.64, df $=8 / 105$, ps $<.05-.01)$. In none of these comparisons, however, were there any reliable group differences ( $\mathrm{Fs}=1.0-2.89, \mathrm{df}=1 / 13$ ) or Groups by Days interactions $(\mathrm{Fs}=1.0-1.49, \mathrm{df}=7-8 / 92-105)$.

The present results, taken in conjunction with earlier observations of daily food and water intake, adaptation to deprivation schedules, and food adulteration (Kemble, unpublished) suggest that daily (though not necessarily short-term) food and water regulatory mechanisms remain essentially intact following damage to the basolateral portion of the amygdala. Similarly, Grossman (1964) found that chemical stimulation in the lateral portions of the amygdala failed to reliably alter food or water consumption. Thus, the present results suggest that the various behavioral deficits resulting from damage to the basolateral amygdala (e.g., Pellegrino, 1968; Pellegrino \& Clapp, 1971; Rolls \& Rolls, 1973) are independent of obvious alterations in daily food and water regulatory mechanisms.

\section{REFERENCES}

Goddard, G. V. Functions of the amygdala. Psychological Bulletin, 1964, 62, 89-109. 
Grossman, S. P. Behavioral effects of chemical stimulation of the ventral amygdala. Journal of Comparative \& Physiological Psychology, 1964, 57, 29-36.

Kemble, E. D. Drive discrimination in rats following amygdaloid lesions. Physiological Psychology, in press.

Kemble, E. D., \& Beckman, G. J. Runway performance of rats following amygdaloid lesions. Physiology \& Behavior, 1970, 5 45-47.

Kemble, E. D., \& Nagel, J. A. Failure to form a learned taste aversion in rats with amygdaloid lesions. Bulletin of the Psychonomic Society, 1973, 2, 155-156.

Kemble, E. D., \& Schwartzbaum, J. S. Reactivity to taste properties of solutions following amygdaloid lesions. Physiology \& Behavior, 1969, 4, 981-985.
Pellegrino, L. J. Am ygdaloid lesions and behavioral inhibition in the rat. Journal of Comparative \& Physiological Psychology, $1968,65,483-491$.

Pellegrino, L. J., \& Clapp, D. F. Limbic lesions and externally cued DRL performance. Physiology \& Behavior, 1971, 7, 863-868.

Rolls, B. J., \& Rolls, E. T. Effects of lesions in the basolateral amygdala on fluid intake in the rat. Journal of Comparative \& Physiological Psychology, 1973, 83, 240-247.

(Received for publication March 25, 1974.) 